\title{
DRUGS IN PREGNANCY
}

\author{
OMAR ABDULWAHID AL-ANI*
}

Department of Clinical Pharmacy, Faculty of Pharmacy, Al-Rafidain University College, Baghdad, Iraq. Email: omralani1987@gmail.com Received: 31 December 2019, Revised and Accepted: 06 April 2020

\begin{abstract}
Objective: During pregnancy, various drugs associated with a contraindication, hence their application is limited and dangerous to mothers along with the fetus. Even though during pregnancy, medication is less preferred but in some instances cannot escape treating the ailments in mother. So here we discussed the medication that can be used safely during pregnancy along with the drugs which are unsafe or highly contraindicated for both mother and the fetus; the problems or complications may be attributed to possible drug interactions during the pregnancy.
\end{abstract}

Methods: The study was conducted from October 2018 until February 2019 in Baghdad, Iraq. It is conducted in four hospitals: Baghdad teaching hospital, Iraqi Red Crescent Society, Saint Raphael (Al Rahibat) Hospital, and Al-Elwiya Educational Hospital. The medical staff in these hospitals assessed for their knowledge about drug effects, complications, and safety during pregnancy. Those medical staff assayed was divided into three groups: Physicians, pharmacists, and other medical staff ( 47 pharmacists, 38 physicians, and 15 nurses who participated in this study).

Results: We found that the majority of doctors and pharmacists useful information on pregnancy categories which is a good indicator of the knowledge of these specialists as the subject of drugs and their impact on pregnant women and the fetus is sensitive and vital because it affects all segments of society.

Conclusion: It is the responsibility of all clinicians, including pharmacists, to counsel patients with complete, accurate, and current information on the risks and benefits of using medications during pregnancy.

Keywords: Pregnant women, Pregnancy category medication, Congenital malformations, Placenta.

(C) 2020 The Authors. Published by Innovare Academic Sciences Pvt Ltd. This is an open access article under the CC BY license (http://creativecommons. org/licenses/by/4. 0/) DOI: http://dx.doi.org/10.22159/ajpcr.2020.v13i6.36746

\section{INTRODUCTION}

Pregnancy is a unique physiological condition where drug treatment presents a particular concern. Careful consideration of the benefit to the mother and the risk to the fetus is required while prescribing drugs during pregnancy [1], the use of drugs during pregnancy calls for special attention because in this case in addition to the mother, the health and life of her unborn child is also at stake. The drugs given to pregnant mothers for therapeutic purposes may cause severe structural and functional adverse effects in the developing child [2]. Since it is tough to determine the effects on the fetus before marketing new drugs due to obvious ethical reasons, most drugs not recommended to use during pregnancy [3]. Drug treatment during pregnancy presents a particular concern due to potential teratogenicity effects of some drugs and physiologic adjustments in the mother in response to pregnancy $[4,5]$. The health and life of her unborn child are also at risk [6]. The drug or metabolite concentration may be even higher in the embryonic or fetus compartment than in the mother. As a result, the fetus as an "additional" patient demands a strict pharmacotherapeutic approach. Total avoidance of pharmacological treatment in pregnancy is not possible. It may be dangerous because some women become pregnant with medical conditions that require ongoing and episodic treatment [5]. Sometimes, drugs are, therefore, essential for the health of the pregnant woman and the fetus. In such cases, a woman should talk with her physician or other healthcare providers about the risks and benefits of taking the drugs. For instance, in chronic conditions such as epilepsy, bronchial asthma, diabetes mellitus [7], or infectious diseases, treatment is obligatory regardless of pregnancy [5]. In contrast, inessential products such as cough preparations, pregnancy supporting substances, high doses of vitamins, and minerals contraindicated as their potential risks outweigh their unproven benefits. Appropriate dispensing is one of the critical steps for rational drug use, including minimizing the use of teratogenicity drugs during pregnancy [8,9]; a drug dispenser must have relevant and updated knowledge and skills regarding the dispensing of drugs during pregnancy. A misperception of the risk may lead to inappropriate decisions for pregnancy outcomes. On the other hand, perception of risk may influence a woman's decision to take a needed drug during pregnancy [10]. There is a general perception that drugs are not safe in pregnancy, even though fewer than 30 drugs shown to cause significant malformations in humans [11]. Avoidance of unnecessary use of drugs during pregnancy, as well as knowledge and awareness of care providers and pregnant women concerning the harmful effect of drugs, is of great significance. Community retail pharmacies represent a readily and easily accessible point of contact for the public where they obtain medicines, drug information, and medical advice $[12,13]$. These premises are particularly crucial in developing countries, where many people do not have medical insurance. Drug dispensers have an essential role in providing correct information and pharmaceutical services to patients, including pregnant women. Since it reported that women generally overestimate the risk of teratogenicity of drugs [14], it is essential for health-care providers, including drug dispensing personnel to use evidence-based information to reduce unnecessary anxiety and to ensure safe and appropriate drug use during pregnancy [10] non-medical exposures to drugs:

Non-medical exposures to drugs during pregnancy occur in suicide gestures (technically a subcategory of substance abuse) and substance abuse (i.e recreational use) suicide gestures occur among approximately $1 \%$ of pregnant women.

As there are numerous gaps in knowledge about deleterious consequences for the fetus, prescription drug use by pregnant women should view as a public health issue. Pharmacoepidemiological studies can measure the extent of prescription and teratogenicity drug use in 
pregnant women. Therefore, in this study, we conducted a field survey to identify the extent to which health service providers know the determinants of drug use during pregnancy.

\section{SUBJECTS AND METHODS}

The study was conducted from October 2018 until February 2019 in Baghdad, Iraq

It is conducted in four hospitals: Baghdad teaching hospital, Iraqi Red Crescent Society, Saint Raphael (Al Rahibat) Hospital, and Al-Elwiya Educational Hospital.

The medical staff in these hospitals assessed for their knowledge about drug effects, complications, and safety during pregnancy. Those medical staff assayed was divided into three groups: Physicians, pharmacists, and other medical staff ( 47 pharmacists, 38 physicians, and 15 nurses participated in this study). The purpose of this study is to what extent the guidelines of drugs in pregnancy followed, which medical staff group is more informed and to attain insights into their experiences when providing medication advice for pregnant women, obtaining further insight into the use of medical drugs that considered to be associated with teratogenicity mechanisms by determining their dispensing rates among pregnant women - because of the limited systemic uptake after topical administration, resulting in a reduced potential to cause congenital disabilities, and locally acting drugs excluded from the survey.

Descriptive statistics are used to describe the basic features of the data in a study. They provide simple summaries about the sample and the measures. Together with simple graphics analysis, they form the basis of virtually every quantitative analysis of data.

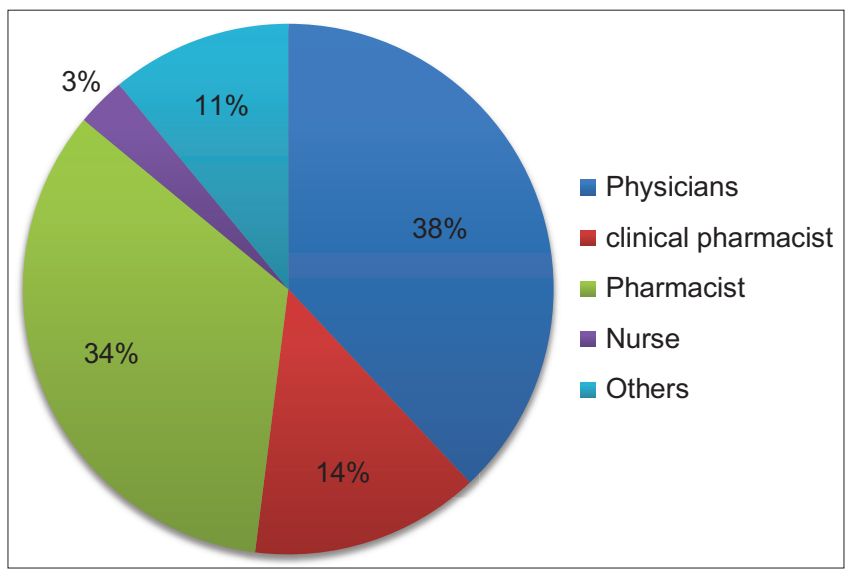

Fig.1: Sample scientific specializing

Table 1: Cronbach's alpha

\begin{tabular}{ll}
\hline Reliability statistics & \\
\hline Cronbach's alpha & Number of items \\
\hline 0.788 & 7 \\
\hline
\end{tabular}

Cronbach's alpha is used to test reliability which refers to the degree to which the results obtained by measurement and procedure can be replicated.

Pearson correlation coefficient shows the validity which expresses the degree to which a measurement measures what it purports to measure. These validity tests are categorized into two broad components, namely, internal and external validities. Internal validity refers to how accurately the measures obtained from the research were quantifying what it was designed to measure, whereas external validity refers to how accurately the measures obtained from the study sample described the reference population from which the study sample was drawn.

\section{Likert scale}

It is a psychometric scale where questions based on this scale are normally used in a survey. It is one of the most widely used question types in a survey.

\begin{tabular}{lll}
\hline Yes & Little bit & No \\
\hline 3 & 2 & 1 \\
\hline
\end{tabular}

We can use Cronbach's alpha to test the reliability of the measurement.

From the previous Table 1, we find that Cronbach's alpha coefficient of the questionnaire axiom equals 0.788 which means the stability of the questionnaire is acceptable if it is returned on the same sample and in the same circumstances.

The Pearson correlation coefficient shows the validity of the questionnaire as the following Table 2 shows the results:

From Table 2, we can see that there is a significant correlation between the axiom and all the statements, as the sig is $<0.05$, so it means that the axiom attains high validity.

From Table 3, we found that $38 \%$ of the samples are physicians, $34 \%$ are pharmacists, $14 \%$ are clinical pharmacists, and $3 \%$ are nurses.

Moreover, the following Fig. 1 shows these results:

From Table 4 , we found that $78 \%$ of the samples are working in hospitals, $12 \%$ are working in the university, and $6 \%$ are working in private pharmacy.

Moreover, the following Fig. 2 shows these results:

Table 5 shows us the trends of the sample opinions toward the statements of the questionnaire, as the sample has a low agreement toward the statement "Do you have any previous information about the pregnancy category Medication?," and a moderate agreement toward the statement "In your opinion, all the risks of drugs can cause congenital Malformations?," and a moderate agreement toward the statement "In your opinion, any drugs can cause fetal toxicity necessarily crosses through the placenta?," and a high agreement toward the statement "according to your knowledge, the warning of medication during pregnancy applied in Iraq?", and a low agreement toward the statement "In your opinion, the subject needs follow-up from the pharmacist

Table 2: Pearson correlation of the axiom and its statements

\begin{tabular}{lll}
\hline & Pearson correlation & Sig. \\
\hline Do you have any previous information about the pregnancy category medication? & $0.403^{* *}$ & 0.000 \\
In your opinion, all the risks of drugs can cause congenital malformations? & $0.390^{* *}$ & 0.000 \\
In your opinion, any drugs can cause fetal toxicity necessarily crosses through the placenta? & $0.502^{* *}$ & $0.338^{* *}$ \\
According to your knowledge, the warning of medication during pregnancy applied in Iraq? & $0.252^{*}$ & 0.000 \\
In your opinion, the subject needs follow-up from the pharmacist syndicate? & $0.393^{* *}$ & 0.001 \\
Do you think it is safe to use any herbal drugs in pregnancy? & $0.389^{* *}$ & 0.011 \\
Do you have any comments you add? & 0.000 \\
\hline
\end{tabular}


syndicate?" and a moderate agreement toward the statement "do you think it is safe to use any herbal drugs in pregnancy?," and a moderate agreement toward the statement "do you have any comments you add?."

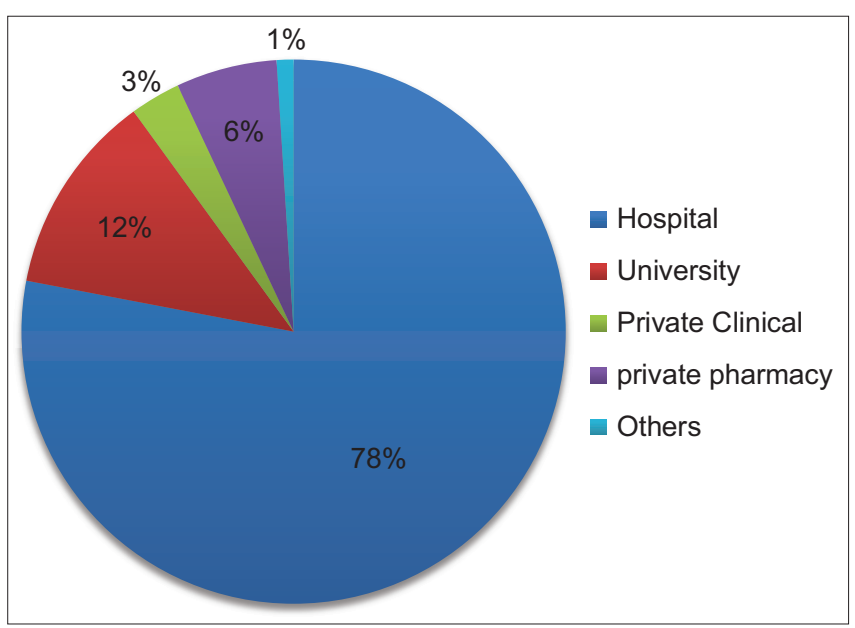

Fig.2: Sample experience

Table 3: Sample scientific specializing

\begin{tabular}{lll}
\hline & Frequency & Percent \\
\hline Physicians & 38 & 38.0 \\
Clinical pharmacist & 14 & 14.0 \\
Pharmacist & 34 & 34.0 \\
Nurse & 3 & 3.0 \\
Others & 11 & 11.0 \\
Total & 100 & 100.0 \\
\hline
\end{tabular}

Table 4: Sample experience

\begin{tabular}{lll}
\hline & Frequency & Percent \\
\hline Hospital & 78 & 78.0 \\
University & 12 & 12.0 \\
Private clinical & 3 & 3.0 \\
Private pharmacy & 6 & 6.0 \\
Others & 1 & 1.0 \\
Total & 100 & 100.0 \\
\hline
\end{tabular}

\section{RESULTS}

The first hypothesis, "there is a significant difference between the sample opinions according to their scientific specializing" (Table 6).

From Table 7, we find that there is a significant difference between the sample opinions according to their scientific specializing, as $\mathrm{p}=0.03$ is $<0.05$, so there is a significant difference between the sample opinions according to their scientific specializing as the high mean is for nurses in the sample.

The second hypothesis, "there is a significant difference between the sample opinions according to their experience" (Table 8).

From Table 9, we find that there is a significant difference between the sample opinions according to their experience, as $p=0.02$ is $<0.05$, so there is a significant difference between the sample opinions according to their experience as the high mean is for private clinical in the sample.

\section{DISCUSSION}

In this study, we found that the subject of the research was important and worthy of study and through the collection of specialized questionnaires prepared previously by researchers claiming that we have obtained useful information serve as a basis for the continuation and development of research in the future to serve the public interest where we found that the majority of doctors and pharmacists useful information of pregnancy categories which is a good indicator of the knowledge of these specialists as the subject of drugs and their impact on pregnant women and the fetus is a sensitive and vital because it affects all segments of society (Table 1), in terms of the risks of drugs to pregnant women, if all these risks are congenital malformations, the opinion of the target in the questionnaire was that it is not necessary that all these risks causing birth defects, but can affect the fetus in other aspects during his life, the extent of knowledge of the medical staff of the impact of these drugs also showed the answers to the importance of the doctor or pharmacist in educating the community about these drugs and the extent of their various effects on the fetus or mother alike, when asked whether all the drugs that are dangerous to the fetus pass through the placenta, the pharmacists' answers were more accurate than the doctors and the other medical staff in the study, indicating that the pharmacists are more familiar with the toxicity of the drug and its interactions within the body and it does not have to be dangerous the medicine is limited to only drugs that pass through the placenta as there are some drugs affect the fetus and do not pass through the placenta. As for the issue of drugs in pregnancy and whether the subject applied in

Table 5: Trends of the sample opinions toward the statements of the questionnaire

\begin{tabular}{|c|c|c|c|c|c|c|}
\hline The statements & Yes & No & Little bit & Mean & SD & The degree \\
\hline \multicolumn{7}{|c|}{ Do you have any previous information about the pregnancy category medication? } \\
\hline Frequency & 74 & 5 & 21 & 1.47 & 0.82 & Low \\
\hline Percent & 74.0 & 5.0 & 21.0 & & & \\
\hline \multicolumn{7}{|c|}{ In your opinion, all the risks of drugs can cause congenital malformations? } \\
\hline Frequency & 8 & 80 & 12 & 2.04 & 0.45 & Moderate \\
\hline Percent & 8.0 & 80.0 & 12.0 & & & \\
\hline \multicolumn{7}{|c|}{ In your opinion, any drugs can cause fetal toxicity necessarily crosses through the placenta? } \\
\hline Frequency & 34 & 50 & 16 & 1.82 & 0.69 & Moderate \\
\hline Percent & 34.0 & 50.0 & 16.0 & & & \\
\hline \multicolumn{7}{|c|}{ According to your knowledge, the warning of medication during pregnancy applied in Iraq? } \\
\hline Frequency & 25 & 30 & 45 & 2.20 & 0.82 & High \\
\hline Percent & 25.0 & 30.0 & 45.0 & & & \\
\hline \multicolumn{7}{|c|}{ In your opinion, the subject needs follow-up from the Pharmacist Syndicate? } \\
\hline Frequency & 79 & 10 & 11 & 1.32 & 0.66 & Low \\
\hline Percent & 79.0 & 10.0 & 11.0 & & & \\
\hline \multicolumn{7}{|c|}{ Do you think it is safe to use any herbal drugs in pregnancy? } \\
\hline Frequency & 7 & 75 & 18 & 2.11 & 0.49 & Moderate \\
\hline Percent & 7.0 & 75.0 & 18.0 & & & \\
\hline \multicolumn{7}{|c|}{ Do you have any comments you add? } \\
\hline Frequency & 22 & 78 & 0 & 1.78 & 0.42 & Moderate \\
\hline Percent & 22.0 & 78.0 & 0 & & & \\
\hline
\end{tabular}


Table 6: Descriptive the difference between the sample opinions according to their scientific specializing

\begin{tabular}{|c|c|c|c|c|c|c|c|c|}
\hline \multicolumn{9}{|l|}{ Descriptive } \\
\hline \multicolumn{9}{|l|}{ The dimension } \\
\hline & \multirow{2}{*}{$\mathbf{n}$} & \multirow{2}{*}{ Mean } & \multirow{2}{*}{ SD } & \multirow{2}{*}{ SE } & \multicolumn{2}{|c|}{$95 \%$ Confidence interval for mean } & \multirow{2}{*}{ Minimum } & \multirow{2}{*}{ Maximum } \\
\hline & & & & & Lower bound & Upper bound & & \\
\hline Physicians & 38 & 13.47 & 1.97 & 0.32 & 12.83 & 14.12 & 9.00 & 18.00 \\
\hline Clinical pharmacist & 14 & 13.14 & 1.70 & 0.46 & 12.16 & 14.13 & 10.00 & 16.00 \\
\hline Pharmacist & 34 & 13.21 & 1.81 & 0.31 & 12.58 & 13.84 & 11.00 & 17.00 \\
\hline Nurse & 3 & 15.33 & 0.58 & 0.33 & 13.90 & 16.77 & 15.00 & 16.00 \\
\hline Others & 11 & 11.82 & 1.66 & 0.50 & 10.70 & 12.94 & 9.00 & 14.00 \\
\hline Total & 100 & 13.21 & 1.89 & 0.19 & 12.83 & 13.59 & 9.00 & 18.00 \\
\hline
\end{tabular}

Table 7: Comparison of basic parameters according to their scientific specializing

\begin{tabular}{llllll}
\hline ANOVA & & & & \\
\hline The dimension & & & & \\
\hline & Sum of squares & df & Mean square & F & p value \\
\hline Between groups & 37.540 & 4 & 9.385 & 2.812 & 0.030 \\
Within groups & 317.050 & 95 & 3.337 & & \\
Total & 354.590 & 99 & & & \\
\hline
\end{tabular}

Significant if the ${ }^{*} \mathrm{p}=0.05$

Table 8: Descriptive the difference between the sample opinions according to their experience

\begin{tabular}{|c|c|c|c|c|c|c|c|c|}
\hline \multicolumn{9}{|l|}{ Descriptive } \\
\hline \multicolumn{9}{|l|}{ The dimension } \\
\hline & \multirow[t]{2}{*}{$\mathbf{n}$} & \multirow[t]{2}{*}{ Mean } & \multirow[t]{2}{*}{ SD } & \multirow[t]{2}{*}{ SE } & \multicolumn{2}{|c|}{$\mathbf{9 5 \%}$ Confidence interval for mean } & \multirow[t]{2}{*}{ Minimum } & \multirow[t]{2}{*}{ Maximum } \\
\hline & & & & & Lower bound & Upper bound & & \\
\hline Hospital & 78 & 13.03 & 1.87 & 0.21 & 12.61 & 13.45 & 9.00 & 18.00 \\
\hline University & 12 & 13.83 & 1.95 & 0.56 & 12.60 & 15.07 & 11.00 & 17.00 \\
\hline Private clinical & 3 & 14.33 & 1.15 & 0.67 & 11.46 & 17.20 & 13.00 & 15.00 \\
\hline Private pharmacy & 6 & 14.17 & 2.04 & 0.83 & 12.02 & 16.31 & 12.00 & 16.00 \\
\hline Others & 1 & 11.00 & & & & & 11.00 & 11.00 \\
\hline Total & 100 & 13.21 & 1.89 & 0.19 & 12.83 & 13.59 & 9.00 & 18.00 \\
\hline
\end{tabular}

Table 9: Comparison of basic parameters according to their scientific experience

\begin{tabular}{lllllll}
\hline ANOVA & & & & & \\
\hline The dimension & & & & & \\
\hline & $\begin{array}{l}\text { Sum of } \\
\text { squares }\end{array}$ & df & $\begin{array}{l}\text { Mean } \\
\text { square }\end{array}$ & F & p value \\
\hline \begin{tabular}{llllll} 
Between groups & 21.475 & 4 & 5.369 & 1.531 & 0.020 \\
Within groups & 333.115 & 95 & 3.506 & & \\
Total & 354.590 & 99 & & & \\
\hline
\end{tabular}
\end{tabular}

Significant if the $* \mathrm{p}=0.05$

Iraq, there was a difference of opinion because of the different bodies and disciplines that belong to the medical staff and the majority of views indicate that the subject is vital and not applied effectively in Iraq and need more attention; the preparation of specialized warning programs on the dangers of using drugs during pregnancy and most pharmacists and doctors say that most mistakes occur in private pharmacies because of the absence of a pharmacist who is often responsible and turning pharmacists into mere drug distributors without giving any advice to patients. Furthermore, the clinical pharmacists have not taken any real and active role in the hospital, all of which led to poor awareness of the risks of drugs during pregnancy. Moreover, when asked about the medicinal herbs used by pregnant women, most of the answers of the medical staff on the seriousness of the use of some of these herbs during pregnancy as they can affect the mother and the fetus at the same time, and stressed that the use of these herbs is widespread in Iraqi society and the majority.

\section{CONCLUSION}

The unique nature of the physiology of pregnancy presents challenges for the pharmaceutical treatment of chronic and acute disorders and symptom management of many complaints associated with pregnancy. It is the responsibility of all clinicians, including pharmacists, to counsel patients with complete, accurate, and current information on the risks and benefits of using medications during pregnancy [15]. Counseling women who have had exposure to drugs about the risk of teratogens involves accurately identifying exposure and quantifying the magnitude of exposure; this may be straightforward for prescribed drugs, but it can be much more difficult with ethanol or other illicit substances or OTC drugs [3]. The use of herbal medicine during pregnancy is a common phenomenon. Different studies revealed that using herbal medicine during the first 12 weeks and the past 12 weeks of gestation is dangerous for the fetus. Pregnant women should consult doctors or pharmacists before using any herbal medicines. The untoward effects of using herbal medicine during pregnancy need further investigation for many herbs. Thus, researches, especially a clinical trial study, should be 
conducted to identify the untoward effect of herbal medicine use during pregnancy. We found through our study that there are some problems in advising pregnant women and not giving importance even though it is dangerous [16]. Therefore, we recommend more attention by the pharmacists syndicate by giving specialized educational courses to all members of the medical staff and women in general and follow-up pharmacists in private pharmacies and health institutions by giving the correct instructions using drugs.

\section{ACKNOWLEDGMENTS}

The author is grateful to the Pharmacy Department, Al-Rafidain University College, especially Pharmacists; Riyam Hameed, Abu Al-Hassan Jamal, and Atheer Jamil.

\section{AUTHORS' CONTRIBUTORS}

Dr. Omar A. Al-Ani selected the topic, research concept development, and guided the research process and manuscript preparation.

Pharmacists; Riyam Hameed, Abu Al-Hassan Jamal, and Atheer Jamil contribute to the collected data.

\section{CONFLICTS OF INTEREST}

There are no conflicts of interest.

\section{REFERENCES}

1. Benjamin DM. Reducing medication errors and increasing patient safety. J Clin Pharmacol 2003;43:768-83.

2. Kacew S. Fetal consequences and risks attributed to the use of prescribed and over-the counter (OTC) preparations during pregnancy. Int J Clin Pharmacol Ther 1994;32:335.

3. Koren G, Pastuszak A, Ito S. Drugs in pregnancy. N Engl J Med 1998;338:1128-37.

4. Czeizel AE. The estimation of human teratogenic/fetotoxic risk of exposures to drugs on the basis of Hungarian experience: A critical evaluation of clinical and epidemiological models of human teratology. Expert Opin Drug Saf 2009;8:283-303.

5. Sachdeva P, Patel BG, Patel BK. Drug use in pregnancy: A point to ponder. Indian J Pharm Sci 2009;71:1-7.

6. Rohra DK, Das N, Azam SI, Solangi NA, Memon Z, Shaikh AM. Drugprescribing patterns during pregnancy in the tertiary care hospitals of Pakistan: A cross sectional study. BMC Pregnancy Childbirth 2008;8:24

7. Ah-Ani OA, Al-Bazzaz A. Glycated low-density lipoprotein in diabetic and non-diabetic patients. Asian J Pharm Clin Res 2019;13:123-6.

8. Andrade SE, Raebel MA, Morse AN, Davis RL, Chan KA, Finkelstein JA. Use of prescription medications with a potential for fetal harm among pregnant women. Pharmacoepidemiol Drug Saf 2006; $15: 546-54$.

9. Lee E, Maneno MK, Smith L, Weiss SR, Zuckerman IH, Wutoh AK. National patterns of medication use during pregnancy. Pharmacoepidemiol Drug Saf 2006;15:537-45.

10. Nordeng H, Ystrøm E, Einarson A. Perception of risk regarding the use of medications and other exposures during pregnancy. Eur J Clin Pharmacol 2010;66:207-14.

11. Pole M, Einarson A, Pairaudeau N, Einarson T, Koren G. Drug labeling and risk perceptions of teratogenicity: A survey of pregnant Canadian women and their health professionals. J Clin Pharmacol 2000;40:573-7.

12. Buurma H, De Smet PA, Egberts AC. Clinical risk management in Dutch community pharmacies: The case of drug-drug interactions. Drug Saf 2006;29:723-32.

13. Toovey S. Malaria chemoprophylaxis advice: Survey of South African community pharmacists' knowledge and practices. J Travel Med 2006;13:161-5.

14. Koren G, Levichek Z. The teratogenicity of drugs for nausea and vomiting of pregnancy: Perceived versus true risk. Am J Obstet Gynecol 2002; 186:248-52.

15. Pangle BL. Drugs in pregnancy and lactation. In: Herfindal ET, Gourley DR, editors. Text Book of Therapeutics, Drug and Disease Management. $8^{\text {th }}$ ed. Philadelphia, PA: Lippincott William Wilkins; 2006. p. 434-48.

16. Katmini, Murti B, Oepomo TD, Anantanyu S. Path analysis on the effect of social capital on the empowerment of pregnant women in pre-eclampsia prevention using precede-proceede in Kediri east Java, Indonesia. Asian J Pharm Clin Res 2018;11:271-3. 